\title{
Large-Eddy Observation of Post-Cold-Frontal Continental Stratocumulus
}

\author{
DAVID B. MECHEM \\ Atmospheric Science Program, Department of Geography, University of Kansas, Lawrence, Kansas \\ YEFIM L. KOGAN \\ Cooperative Institute for Mesoscale Meteorological Studies, University of Oklahoma, Norman, Oklahoma
}

DAVID M. SCHULTZ

Division of Atmospheric Sciences and Geophysics, Department of Physics, University of Helsinki, and Finnish Meteorological Institute, Helsinki, Finland, and Centre for Atmospheric Sciences, School of Earth, Atmospheric and Environmental Sciences, University of Manchester, Manchester, United Kingdom

(Manuscript received 20 November 2009, in final form 16 April 2010)

\begin{abstract}
More studies on the dynamics of marine stratus and stratocumulus clouds have been performed than comparable studies on continental stratocumulus. Therefore, to increase the number of observations of continental stratocumulus and to compare marine and continental stratocumulus to each other, the approach of large-eddy observation (LEO) was applied to a case of nocturnal continental stratocumulus observed over the Atmospheric Radiation Measurement Program (ARM) Climate Research Facility (ACRF) in the central United States on 8 April 2006. The stratocumulus occurred in cold-air and dry-air advection behind a surface cold front. LEOs were obtained from millimeter-wavelength cloud radar and micropulse lidar, whereas traditional meteorological observations described the synoptic environment. This study focuses on a 9-h period of a predominantly nonprecipitating stratocumulus layer $250-400 \mathrm{~m}$ thick. A slight thinning of the cloud layer over time is consistent with dry-air advection. A deep layer of descent overlaid a shallower layer of ascent from the surface up to $800 \mathrm{mb}$, providing a mechanism for strengthening the inversion at cloud top. Time series of Doppler velocity indicate vertically coherent structures identifiable throughout much of the cloud layer. The magnitude of turbulence, as indicated by the variance of the vertical velocity, was weak relative to typical marine stratocumulus and to the one other case of continental stratocumulus in the literature. Conditional sampling of the eddy structures indicate that strong downdrafts were more prevalent than strong updrafts, and negative skewness of vertical velocity in the cloud implies an in-cloud circulation driven by longwave cooling at cloud top, similar to that in marine stratocumulus.
\end{abstract}

\section{Introduction}

Much of the considerable uncertainty in simulations of future climate change scenarios can be attributed to differences in how low-altitude clouds are represented in global climate models (e.g., Bony and Dufresne 2005; Medeiros et al. 2008; Williams and Webb 2009). Specifically, extensive regions of stratocumulus located in eastern oceanic basins significantly impact the shortwave radiation budget (e.g., Ramanathan et al. 1989;

Corresponding author address: David B. Mechem, Atmospheric Science Program, Department of Geography, University of Kansas, 1475 Jayhawk Blvd., 213 Lindley Hall, Lawrence, KS 66045-7613. E-mail:dmechem@ku.edu
Klein and Hartmann 1993). These low-level marine stratocumulus clouds predominantly exist under the subsiding branch of the Hadley circulation in quiescent regions of high pressure. As such, the lower-tropospheric environment is characterized as largely horizontally homogeneous, subsiding, and very nearly barotropic (or equivalent barotropic).

Stratocumulus clouds are not solely associated with surface high pressure systems but also can accompany midlatitude cyclones. Field and Wood (2007) composited satellite and reanalysis data to construct mean fields characteristic of midlatitude oceanic cyclones. Although their analysis was performed over the ocean, presumably much of their basic cyclone structure applies over continental regions as well. Among other conclusions, their 

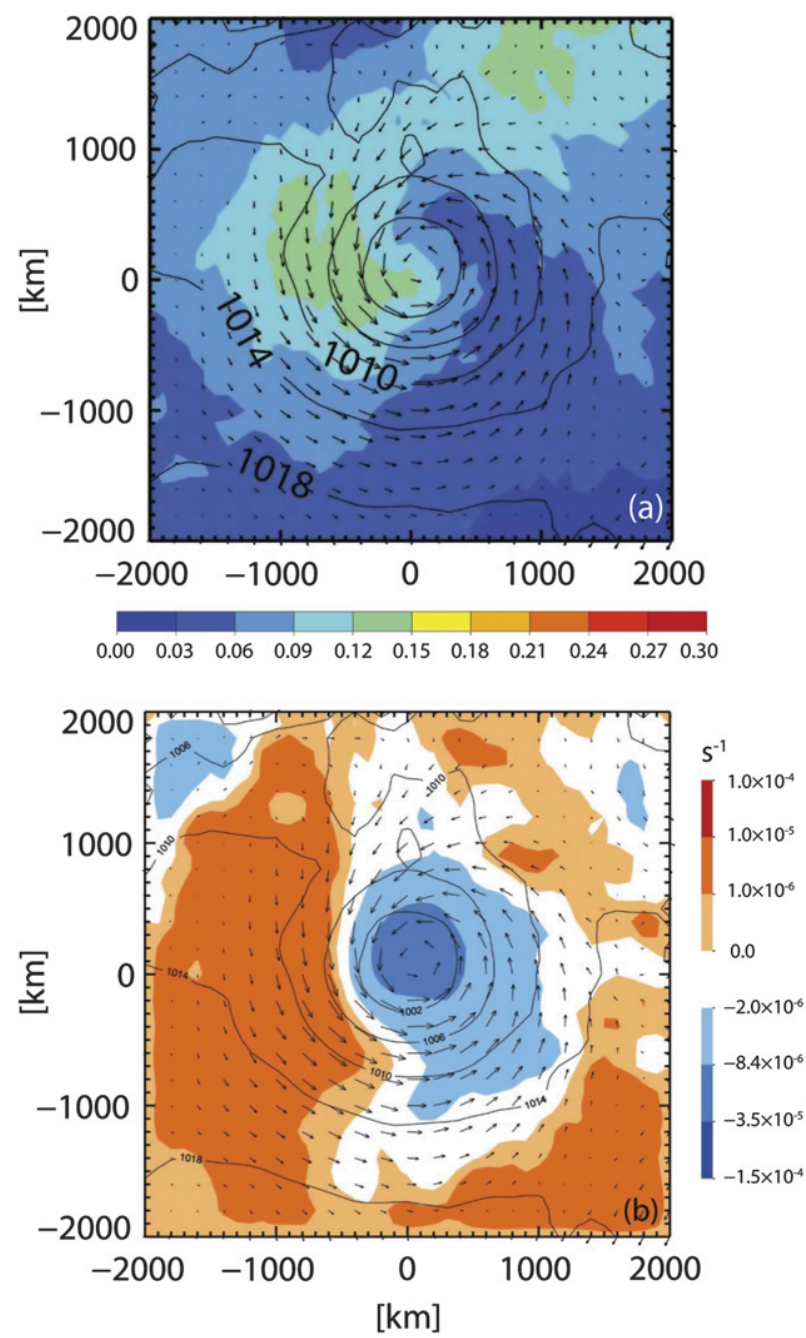

FIG. 1. Adapted from Field and Wood (2007, their Figs. 4b and 5). Solid lines are sea level pressure every $4 \mathrm{mb}$. (a) Average stratocumulus cloud fraction. (b) Average surface divergence.

results demonstrate that midlatitude cyclones are accompanied by broad areas of stratocumulus located behind the cold front, west and north of the low center (Fig. 1a). The synoptic environment of these clouds is fundamentally different from that of classic marine stratocumulus described by Klein and Hartmann (1993).

Thus, we suggest that there might be a distinction between marine and continental stratocumulus, where the characteristic scale of horizontal variability near midlatitude cyclones is smaller than that near marine subtropical anticyclones. For example, much of the composite stratocumulus cloud cover in Fig. 1 is located under surface divergence, although closer to the low center, convergence dominates (Fig. 1b). Stratocumulus accompanying extratropical cyclones are therefore present in regions of upward, downward, and near-zero vertical motion. ${ }^{1}$ Because of this variability, the approximate balance between entrainment and subsidence found over marine boundary layers (Wood and Bretherton 2004; Faloona et al. 2005) may not generally apply.

The vast majority of the literature aimed at understanding boundary layer cloud dynamics applies to maritime clouds, with comparatively little explicitly addressing continental clouds. Employing satellite and surface-based remote sensing, Del Genio and Wolf (2000) assessed the similarities and differences between continental and marine boundary layer clouds. Although their terminology is somewhat different from ours (what we term stratocumulus they refer to as "thick stratus"), they concluded that much of what is known about boundary layer stratocumulus over oceanic regions applies over the continent, with some exceptions. They cite differences in surface characteristics, specifically the constant moisture source of the ocean and the short thermal-response time scale of the land surface, and point out that continental stratocumulus clouds are transient relative to their maritime counterparts. In a mixed-layer budget study of stratocumulus over the southeastern Pacific, Caldwell et al. (2005) found that the magnitude of the surface moisture flux was 2-3 times that of horizontal advection, and of opposite sign. The absence of the oceanic moisture source in the continental cases implies that the boundary layer water budget is dominated by advection rather than surface fluxes.

The installation of a millimeter-wavelength Doppler cloud radar (MMCR) in the mid-1990s at the Atmospheric Radiation Measurement Program (ARM) Climate Research Facility (ACRF) Southern Great Plains (SGP) site in northern Oklahoma has been a boon to cloud studies, since the radar is capable of sensing multilayer cloud structures that passive radiometric techniques cannot. Clothiaux et al. (1995) discussed how MMCRs might be employed for retrievals of cloud properties. Many subsequent studies explored these and other specific methods to retrieve cloud system properties from radar data and employed these retrieved quantities to focus on cloud structure or climatology [e.g., Frisch et al. (1995a); Babb et al. (1999); Sassen et al. (1999); Chin et al. (2000); Kato et al. (2001); Dong et al. (2005); Kim et al. (2005), which is by no means an exhaustive list].

Whereas these previous studies focused on the mean properties of cloud behavior, boundary layer clouds in reality are an intrinsic part of the turbulent flow consisting of updrafts, downdrafts, and entrainment. Past

\footnotetext{
${ }^{1}$ Recent results suggest that significant horizontal variability in subsidence divergence accompanies marine boundary layer clouds as well, even where the cloud fields are visibly homogeneous from satellite (e.g., Fig. 3 in Stevens et al. 2007).
} 
studies thus generally documented cloud properties with little concern for cloud dynamics associated with (and oftentimes driving) the cloud properties. Recognizing that the cloud droplets serving as Rayleigh scatterers have near-negligible fall speeds and inertia so that they may represent passive tracers of the flow, cloud radars have begun to be used for studies of boundary layer turbulence.

Frisch et al. (1995b) was the first to apply profiling Doppler cloud radar to investigate turbulent flows in stratocumulus. They used a 35-GHz ( $\mathrm{K}_{\alpha}$ band) MMCR during the Atlantic Stratocumulus Transition Experiment (ASTEX), based in the Azores, to obtain variance and skewness profiles for boundary layer clouds. Profiles of vertical velocity variance exhibited diurnal variability and contained multiple maxima. Skewness in the upper part of the cloud was negative, transitioning to positive skewness in the lower part of the cloud.

Most applicable to our present study is the work of Kollias and Albrecht (2000), who analyzed continental stratocumulus over central Pennsylvania sampled by a 94-GHz cloud radar. Recognizing the utility of these high-resolution radar observations for verification of large-eddy simulation (LES), Kollias and Albrecht introduced the term large-eddy observations (LEOs) to describe sampling of the atmosphere at sufficient spatial and temporal resolution to capture the turbulent flow structures. The term LEO in principle encompasses a wide range of instrumentation, from sonic anemometers for obtaining turbulent fluxes via eddy correlation, to Doppler cloud radars. Kollias and Albrecht specifically refer to cloud radars, and, in the spirit of their term, Doppler cloud radar data form the basis for LEOs in this paper.

We employ LEO and methods previously applied for marine stratocumulus to a case of continental boundary layer stratiform cloud observed over the central United States. In addition to increasing the number of observations of continental stratocumulus, the driving questions for our study are the following:

- How do radar reflectivity and velocity observations for this case compare with the continental stratocumulus observed by Kollias and Albrecht (2000)?

- What are the similarities and differences between continental and marine boundary layer clouds, as illuminated by cloud radar?

- Ultimately, what is the value of using LEOs combined with routine meteorological observations for investigating boundary layer stratocumulus?

This work is complemented by a large-eddy simulation approach, which will be presented in a separate paper (Mechem et al. 2010).

\section{Data and methods}

This study revolves around the post-cold-frontal, lowaltitude cloud system that passed over the ACRF SGP site in northern Oklahoma on 8 April 2006 (location denoted by the star in Fig. 2). The case of 8 April 2006 was selected from the W-Band ARM Cloud Radar (WACR) archive because of the long, continuous presence $(>9 \mathrm{~h}$ ) of clouds sampled by radar and the apparent similarity to other stratus and stratocumulus clouds previously observed at the ARM site (e.g., Dong et al. 2005; Kim et al. 2005). Although we were not able to visually identify patches or billows characteristic of stratocumulus, the observations we describe (specifically the turbulent vertical motions in the cloud) are otherwise characteristic of the stratocumulus genera. This result leads us to use "stratocumulus" to describe this cloud system, which is consistent with the prevalent use of the term in the literature.

The ACRF hosts an extensive suite of instruments to characterize the relationship between clouds, aerosol, and radiation. The centerpiece instrument for this article is the $95-\mathrm{GHz}$ (3-mm wavelength) WACR (Widener and Johnson 2006). Kollias et al. (2007a,b) describe the ARM cloud radar effort in detail, concentrating on the longer-wavelength $35-\mathrm{GHz}$ radars that have long been a part of ARM's observational strategy. The WACR is a profiling cloud radar that provides reflectivity factor (which we refer to simply as "reflectivity"), Doppler velocity, and spectrum width (the zeroth, first, and second moments of the Doppler spectrum) measurements for scatterers in the cloud-drop size range. Peak radar power is $1.5 \mathrm{~kW}$, transmitted via a $0.61-\mathrm{m}$ antenna for a beamwidth of $0.38^{\circ}(6.7 \mathrm{~m}$ at a range of $1 \mathrm{~km})$. A pulse length of approximately $0.3 \mu$ s determines the gate spacing of $42.9 \mathrm{~m}$. The pulse repetition frequency of $10 \mathrm{kHz}$ gives a Nyquist velocity of $7.9 \mathrm{~m} \mathrm{~s}^{-1}$. Although the raw spectra files are archived, for this study we rely on the reflectivity and velocity moments. A near-field correction is applied at a range of up to $228 \mathrm{~m}$ from the radar. The magnitude of uncertainty of the radar measurements is estimated to be $0.5 \mathrm{~dB} Z$ for reflectivity and $0.1 \mathrm{~m} \mathrm{~s}^{-1}$ for Doppler velocity (Widener and Johnson 2006).

The radar data were minimally processed to remove signal noise and unphysical Doppler velocity values. Reflectivity values smaller than $-40 \mathrm{~dB} Z$, a limit that in our experience roughly delineates useful boundary layer cloud signals from noise, have been eliminated. Furthermore, because velocity estimates are unreliable in regions where the reflectivity is less than $-35 \mathrm{dBZ}$, they are eliminated as well. Precipitation was filtered out by eliminating scans where reflectivity was greater than $-20 \mathrm{dBZ}$. This ensures that the Doppler velocities represent the air 

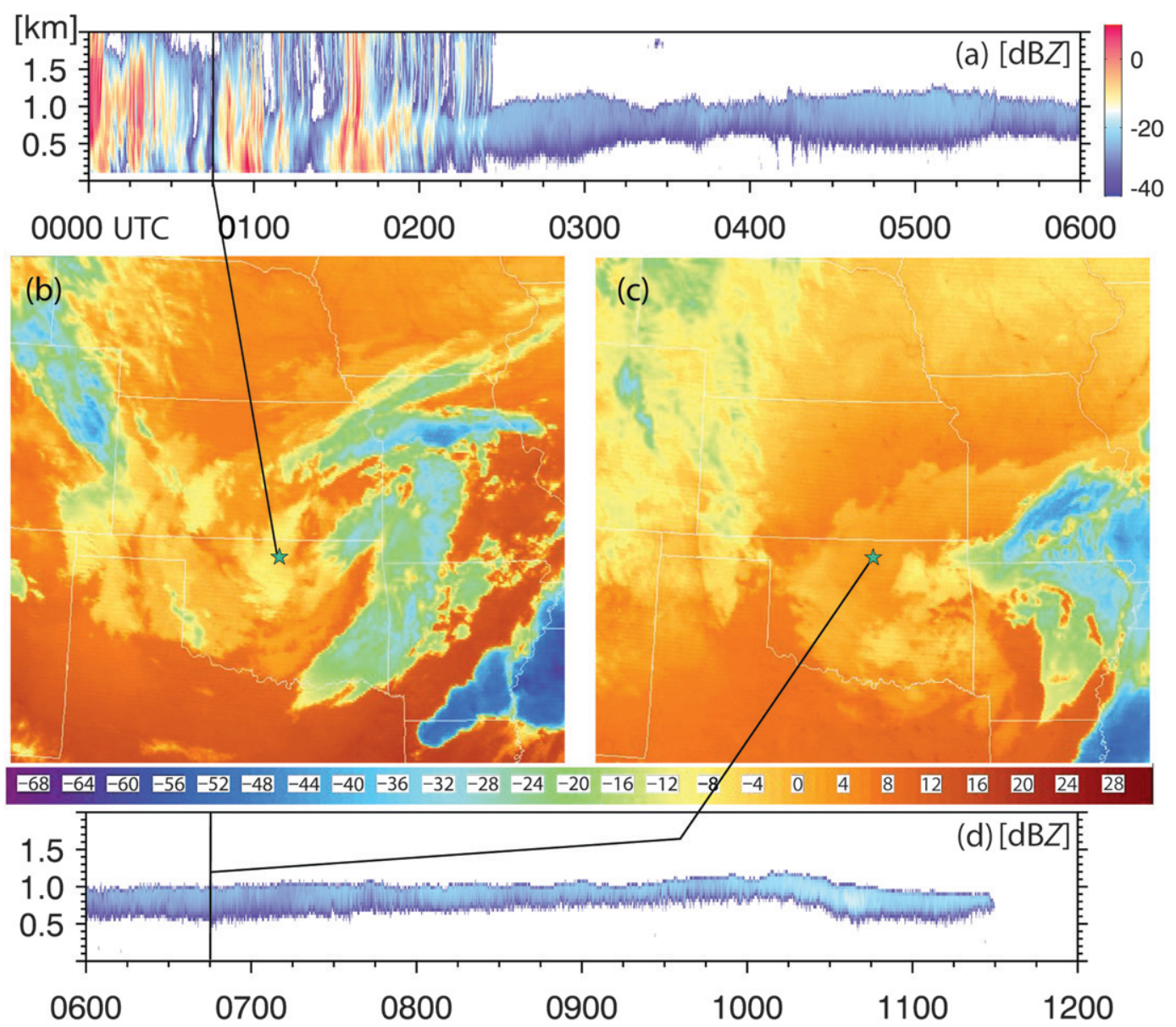

FIG. 2. Satellite imagery and WACR time-height plots of reflectivity from 8 Apr 2006. (a) WACR reflectivity from 0000 to 0600 UTC. GOES longwave infrared channel 4 images corresponding to (b) 0045 and (c) 0645 UTC. (d) WACR reflectivity from 0600 to 1200 UTC.

motion and not a combination of air motion and precipitation sedimentation. A number of thresholds have been used previously to delineate clouds from precipitation (Chin et al. 2000; Kato et al. 2001; Kogan et al. 2005; Liu et al. 2008), and we chose a value of $-20 \mathrm{dBZ}$ to screen out most precipitation-sized particles. Only a small fraction of scans were filtered out during the 06001200 UTC period of interest.

Cloud base was estimated from the micropulse lidar, which employs a low-power, eye-safe laser that operates at a wavelength of $523 \mathrm{~nm}$. Range resolution of the micropulse lidar is $30 \mathrm{~m}$, with the minimum detection distance being about $300 \mathrm{~m}$. Cloud bases in our case are nearly always above this threshold height. Cloud base is estimated by taking 30-s averages of micropulse lidar quantities. Path-integrated liquid water is obtained from a dual-channel microwave radiometer operating at 23.8 and $31.4 \mathrm{GHz}$, with retrieval errors of path quantities estimated to be $\sim 20 \%$ (Hogg et al. 1983).
Vertical atmospheric profiles were taken by a rawinsonde system operated at the ACRF. Surface fluxes of heat, moisture, and momentum were obtained from the eddycorrelation flux-measurement system, which comprised a sonic anemometer to obtain the three-dimensional components of the wind and air temperature, and an open-path infrared gas analyzer to obtain the water vapor density.

To illustrate the synoptic and mesoscale environment of the stratocumulus, we employ output from the Rapid Update Cycle (RUC) analysis system (Benjamin et al. 2004a,b). The RUC has 20-km grid spacing, which is presented here at the degraded grid spacing of $40 \mathrm{~km}$ that was sent to operational forecast offices in real time. The RUC analyses have the advantage of portraying the three-dimensional synoptic and mesoscale structure and evolution of the atmosphere by assimilating asynoptic observations from a multitude of operational and nonoperational observational instruments (e.g., satellite, radar, aircraft reports) into a first-guess field from 

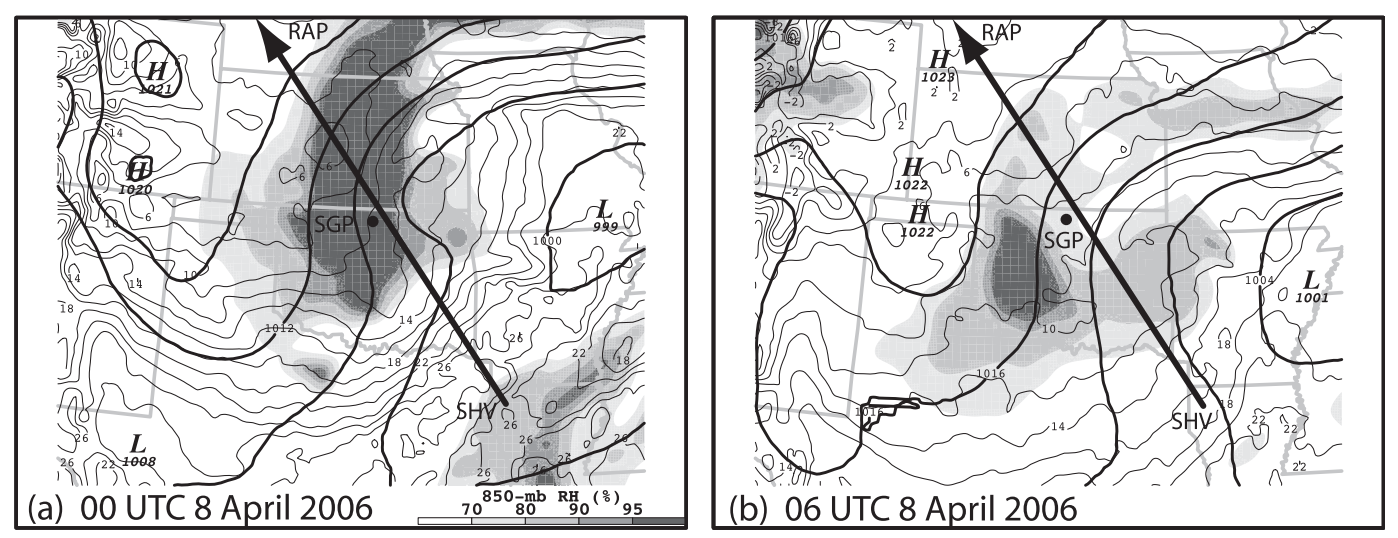

FIG. 3. RUC surface temperature (thin solid lines, every $2 \mathrm{~K}$ ), sea level pressure (thick solid lines, every $4 \mathrm{mb}$ ), and 850 -mb relative humidity (shaded at $70 \%, 80 \%, 90 \%$, and $95 \%$ ). Long thick arrows indicate locations of vertical cross sections shown in Fig. 5. (a) 0000 UTC 8 Apr 2006. (b) 0600 UTC 8 Apr 2006.

a numerical weather prediction model, a distinct advantage relative to the comparatively sparse hourly surface and twice-daily upper-air observations. As such, the RUC output illustrates the large-scale conditions under which the stratocumulus occurs.

\section{Synoptic and mesoscale analysis}

The stratocumulus was occurring to the west of a southeastward-moving surface cyclone over southeastern Missouri at 0000 UTC 8 April 2006 (Fig. 3a). Note that LST $=$ UTC $-6 \mathrm{~h}$, with sunrise and sunset occurring at 1206 and 0059 UTC, respectively. Relative humidity at $850 \mathrm{mb}$ (roughly the height of cloud top) shows a cyclonically curved region of near-saturation extending from northern Oklahoma northward through Kansas and Nebraska and eastward into Iowa. The shape and location of this near-saturated region was similar to the maximum in stratocumulus cloud fraction in the Field and Wood (2007) composite (Fig. 1a). By 0600 UTC, the region of high $850-\mathrm{mb}$ relative humidity had decreased in area and moved southward and eastward, following the movement of the surface cyclone center (Fig. 3b).

Twelve hours of WACR data, along with two Geostationary Operational Environmental Satellite (GOES) longwave infrared images (corresponding to wavelengths of 10.2-11.2 $\mu \mathrm{m}$ ), are shown in Fig. 2. Before 0225 UTC, the WACR data indicate precipitation and a variable cloud-top height (Fig. 2a), consistent with the cloud-top temperatures over northern Oklahoma and southern Kansas from satellite imagery at 0045 UTC (Fig. 2b). Over the next $9 \mathrm{~h}$ after 0225 UTC, the WACR observed a quiescent, slowly varying, nonprecipitating cloud system that resembled marine stratocumulus (e.g., Fig. 2a in van Zanten et al. 2005). The disappearance of echo after 1130 UTC arose not from dissipation of the cloud but rather from the passing of the back edge of the cloud field over the ARM site.

The change in cloud properties sampled by the radar in a Eulerian (fixed in space) framework was a combination of both the local evolution of the cloud moving with the flow, plus advection. The profiling radar by itself cannot distinguish between these two effects; hence the radar cannot unambiguously determine cloud lifetime. GOES imagery indicates that cloud lifetime, estimated by the persistence of low cloud in the postfrontal region of the synoptic system, was $\sim 30 \mathrm{~h}$ in this case. By employing additional data sources (rawinsondes, surface data, model analysis fields), however, our results suggest that advection is the dominant mechanism explaining local evolution of the cloud field.

During 0225-0600 UTC, the WACR data indicates that both cloud-base height and cloud-top height each varied by a couple hundred meters (Fig. 2a). The variation in cloud-base height was most likely due to weak precipitation, which is evident from the Doppler velocity moment (not shown) and the protuberances hanging from the cloud base. The reason for the variation in cloud-top height is unknown but may be related to the relatively weak capping inversion represented by the 0533 UTC sounding (Fig. 4a).

After 0600 UTC, the WACR data show that both cloud-base height and cloud-top height became more steady in time (Fig. 2d), confirmed by the horizontal homogeneity of the cloud-top temperature at 0645 UTC (Fig. 2c) and the strong capping inversion of $8 \mathrm{~K}$ in potential temperature at 0743 and 0838 UTC (Fig. 4a). After about 0730 UTC, the cloud base rose. Finally, after 1000 UTC, the cloud layer dropped by $300 \mathrm{~m}$, visible in the 1129 UTC sounding in Fig. 4, and finally disappeared over SGP at 1130 UTC (Fig. 2d).

As the RUC output shows (Fig. 3), the stratocumulus was located in a region of geostrophic northerlies and 

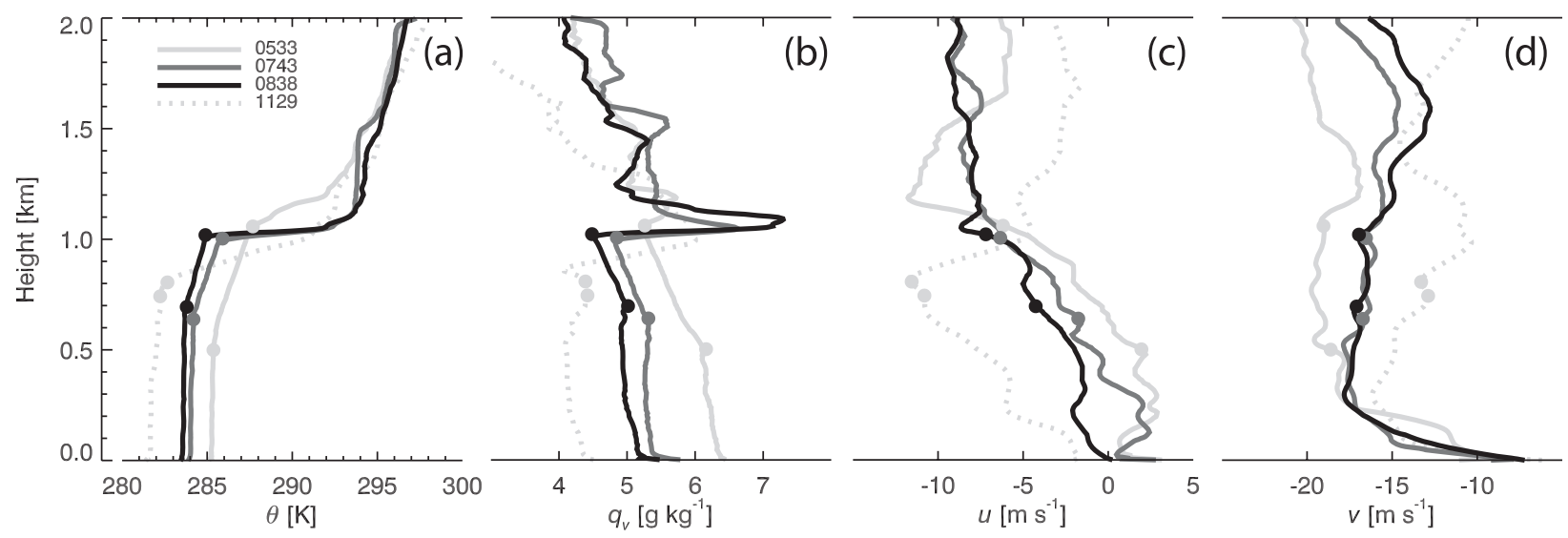

FIG. 4. Soundings of (a) potential temperature, (b) water vapor mixing ratio, (c) $u$ wind, and (d) $v$ wind taken at the ACRF Central Facility at the indicated times. Filled circles represent estimates of cloud base and cloud top for each sounding time. We suspect the thin layer of high mixing ratio just above the inversion is due to the effects of sensor wetting as the sonde breaks into the clear region above cloud top.

cold advection. Vertical cross sections running from Rapid City, South Dakota (RAP), in the northwest, through SGP, to Shreveport, Louisiana (SHV), in the southeast show the vertical structure of the cold front and static stability from the RUC output (Fig. 5). At 0000 UTC (Fig. 5a), the cold front northwest of SHV is indicated by near-surface vertical isentropes and a narrow, intense region of ascent (indicated by the dashed, filled contours), as in observations (summarized in Schultz 2008) and models of the leading edge of cold fronts (e.g., Schultz and Roebber 2008). Behind the surface front to RAP was mostly descent throughout the troposphere. A region of high $(>95 \%)$ relative humidity, extending up to as high as $700 \mathrm{mb}$, was associated with the precipitating clouds in the satellite imagery and WACR data, as occurred before 0225 UTC (Figs. 2a,b).

By 0600 UTC (Fig. 5b), the surface cold front had passed outside of the cross section, and much of the troposphere was dominated by subsidence. Curiously, however, the 900-800-mb stable layer above SGP was characterized by weak ascent. Although the reason for this ascent is not known, in combination with the subsidence that extended from just above the stable layer $(\sim 800 \mathrm{mb})$ upward to at least $300 \mathrm{mb}$, this descent-over-ascent couplet was likely partially responsible for intensifying the inversion, as evident in the soundings between 0533 and 0743 UTC (Fig. 4a). A small region of relative humidity exceeding $90 \%$ occurred underneath the inversion, perhaps an indication of the inability of the RUC to resolve such thin boundary layer clouds.

\section{Large-eddy observations}

By 0600 UTC, the WACR observed boundary layer cloud, whose properties remained steady over several hours (Fig. 6). As mentioned above, the radar samples a combination of cloud system advection, along with any mechanistic (internal) change to the cloud properties. During 0600-1000 UTC, cloud thickness ranged from $250 \mathrm{~m}$ to nearly $400 \mathrm{~m}$, generally thinning with time. Cloud top was estimated by echo-top height, whereas cloud base was obtained by the micropulse lidar. This estimate of cloud base was consistently higher than the reflectivity base (Fig. 6a). This difference could arise from weak precipitation falling below cloud base, which the micropulse lidar did not observe. Specifically, Kim et al. (2005) found that the lowest radar echo lies below the cloud base sensed by ceilometer and lidar, because the radar is highly sensitive to the few large precipitation drops falling below cloud base. The small reflectivities (less than $-20 \mathrm{dBZ}$ ) and lack of systematic descent in this case (Fig. 6b), however, suggest that very little, if any, precipitation was present. Although cloud-base estimates from radar and lidar generally agree for nonprecipitating clouds (Kim et al. 2005), the possibility remains of slight differences in sensitivity between the two instruments.

Standard deviations of cloud base and cloud top $\left(\sigma_{\mathrm{cb}}=\right.$ $20 \mathrm{~m}$ and $\sigma_{\mathrm{ct}}=38 \mathrm{~m}$, respectively, over 0700-1000 UTC) are on the low end of cloud-base and cloud-top variability calculated from 12 continental stratocumulus cases in Kim et al. (2005), who found $\sigma_{\mathrm{cb}}$ ranging over 15-227 m and $\sigma_{\mathrm{ct}}$ ranging over 45-106 m.

The velocity field was highly variable, and the radar captured periods of upward and downward motion, with different scales in evidence (Fig. 6b). Here we follow meteorological convention of positive magnitudes of velocity representing upward vertical motion. Cloud top varied as well, as previously noted, though the resolution was limited by the radar range-gate size of about $43 \mathrm{~m}$. By virtue of the reflectivity thresholding, precipitation-size 

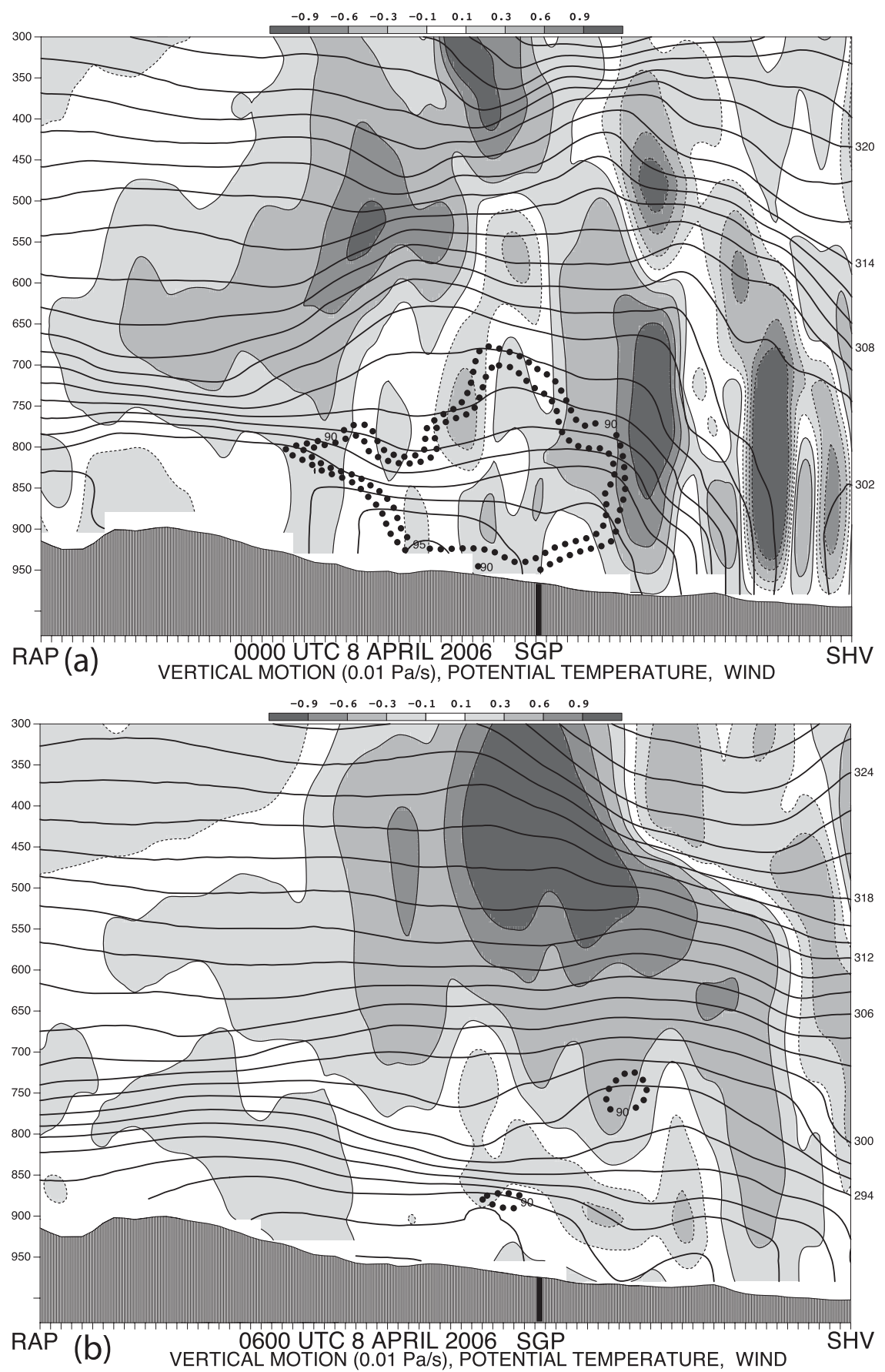

FIG. 5. RUC vertical cross section, taken from Shreveport, LA, to Rapid City, SD (cross section indicated by the thick long arrows in Fig. 3), of potential temperature (solid lines, every $2 \mathrm{~K}$ ), vertical velocity ( $0.01 \mathrm{~Pa} \mathrm{~s}^{-1}$, shaded according to scales, with dashed contours indicating negative values of $\omega$ or ascent), and humidity (large dotted contours at $90 \%$ and $95 \%$ ). Tick marks along the horizontal axis are every $40 \mathrm{~km}$.

droplets were filtered out, meaning the positive and negative values in Fig. $6 \mathrm{~b}$ represent upward and downward turbulent boundary layer eddies. These flow structures have been commonly observed in the many studies on marine stratocumulus (e.g., Vali et al. 1998; Stevens et al. 2003; van Zanten et al. 2005), as well as in one study of continental boundary layer clouds (Kollias and Albrecht 2000). 


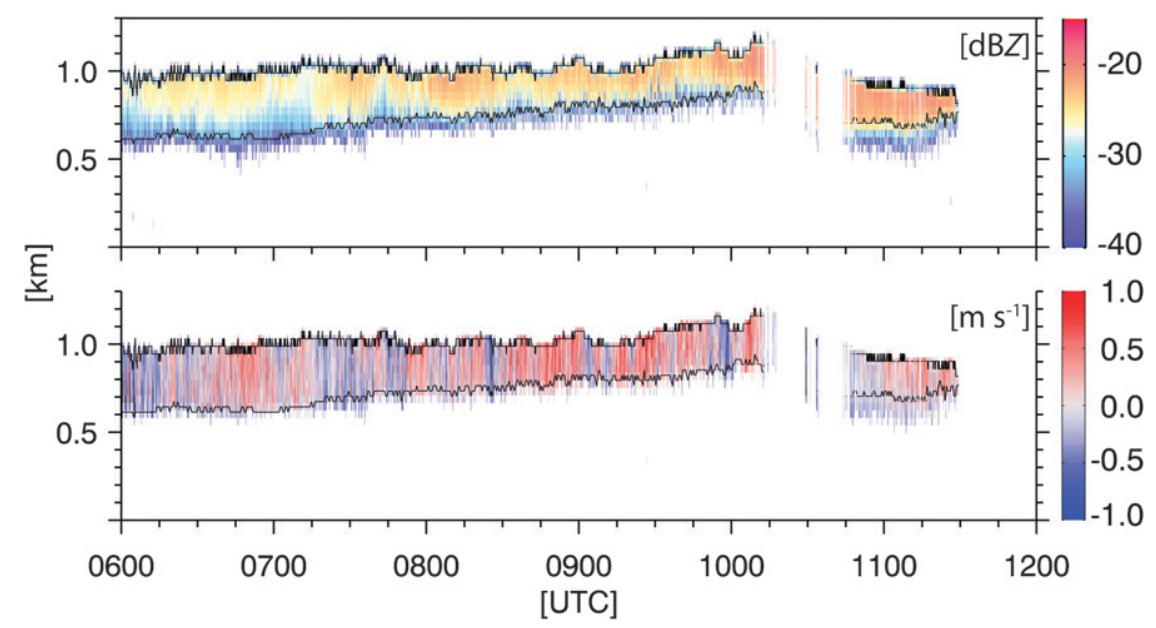

FIG. 6. Processed WACR reflectivity and Doppler velocity from 0600 to 1200 UTC. Black lines indicate estimates of cloud-base and cloud-top heights. Positive values indicate upward vertical velocity.

\section{a. Description of cloud system structure and evolution}

Details of the turbulent flow structures from the Doppler velocity field and selected meteorological variables from 0500 to 1000 UTC are presented in Fig. 7. The hour 0500-0600 UTC is included to illustrate the transition to the period of stratocumulus. Time series of range-gate velocities (at the indicated heights) and cloud boundaries illustrate the cloud slowly thinning with time, particularly by the rise of cloud base (Fig. 7a). A mixed-layer perspective would interpret thinning to arise from boundary layer drying, warming, or some combination of both. RUC model output (Figs. 3 and 5), sounding data (Fig. 4), and surface observations (Figs. 7c,d) indicate cooling over the period, although the cold-air advection after 0600 UTC indicated by the RUC tended to decrease as time progressed (Fig. 7d). The soundings indicate that the near-surface air dried with time, whereas the RUC moisture hardly changed over the entire period (Fig. 7e). Moisture advection, calculated from the RUC, and tendencies from surface observations show an increase of drying with time (Fig. 7f). Although such cooling and drying could be due to surface fluxes, the surface sensible heat was negligible, and the latent heat flux was about $20 \mathrm{~W} \mathrm{~m}^{-2}$. Given the postfrontal cold advection and drying, with reasonable confidence we can conclude that the cloud layer was thinner predominantly because it was drier. The microwave radiometer retrieval of liquid water path in Fig. $7 \mathrm{~b}$ confirms that from 0500 to 0900 UTC cloud thinning was associated with lower values of liquid water path, as would be expected. A slight increase in LWP from 0900 to 1000 UTC accompanied an increase in cloud thickness, before the cloud rapidly thinned over the 1000-1130 UTC period. The result that the advective tendencies are consistent with the cloud behavior suggests that cloud system evolution was dominated by advective processes rather than by internal cloud dynamical mechanisms such as entrainment. The large-scale vertical motion field in the cloud layer (not present in the time series but evident in Fig. 5b) was characterized by weak ascent, an environment quite different from the strong subsidence typically found in marine stratocumulus.

Cloud base and cloud top varied considerably over the 0500-1000 UTC period. Cloud base was relatively steady from 0500 to 0700 UTC but then rose over the next $3 \mathrm{~h}$. Cloud top dropped about $250 \mathrm{~m}$ during 0500 0600 UTC, as a thicker, drizzling portion of the cloud system passed over the radar and the cloud subsequently transitioned to nonprecipitating stratocumulus. Cloud top ascended and descended over the next $4 \mathrm{~h}$ from 0600 to 1000 UTC. Radar estimates of cloud top are consistent with those obtained from soundings. Cloud bases obtained via micropulse lidar, however, were consistently overestimated (by over $100 \mathrm{~m}$ in one of the cases; Fig. 7a). The lifting condensation level (LCL; dotted gray line in Fig. 7a), calculated from surface observations of temperature and moisture, was lower than cloud-base estimates from sounding, lidar, or radar. The discrepancy between LCL and cloud base suggests that the cloud layer was to some extent, thermodynamically distinct from the subcloud layer.

The cloud structure is reflected in mean reflectivity profiles from every other hour (Fig. 8). The 05000600 UTC profile in particular does not exhibit the sharp gradient at cloud top because of averaging over the variability in the cloud top (Fig. 7a). The temperature profile in Fig. 4a in the 0533 UTC sounding possesses a gradual, 


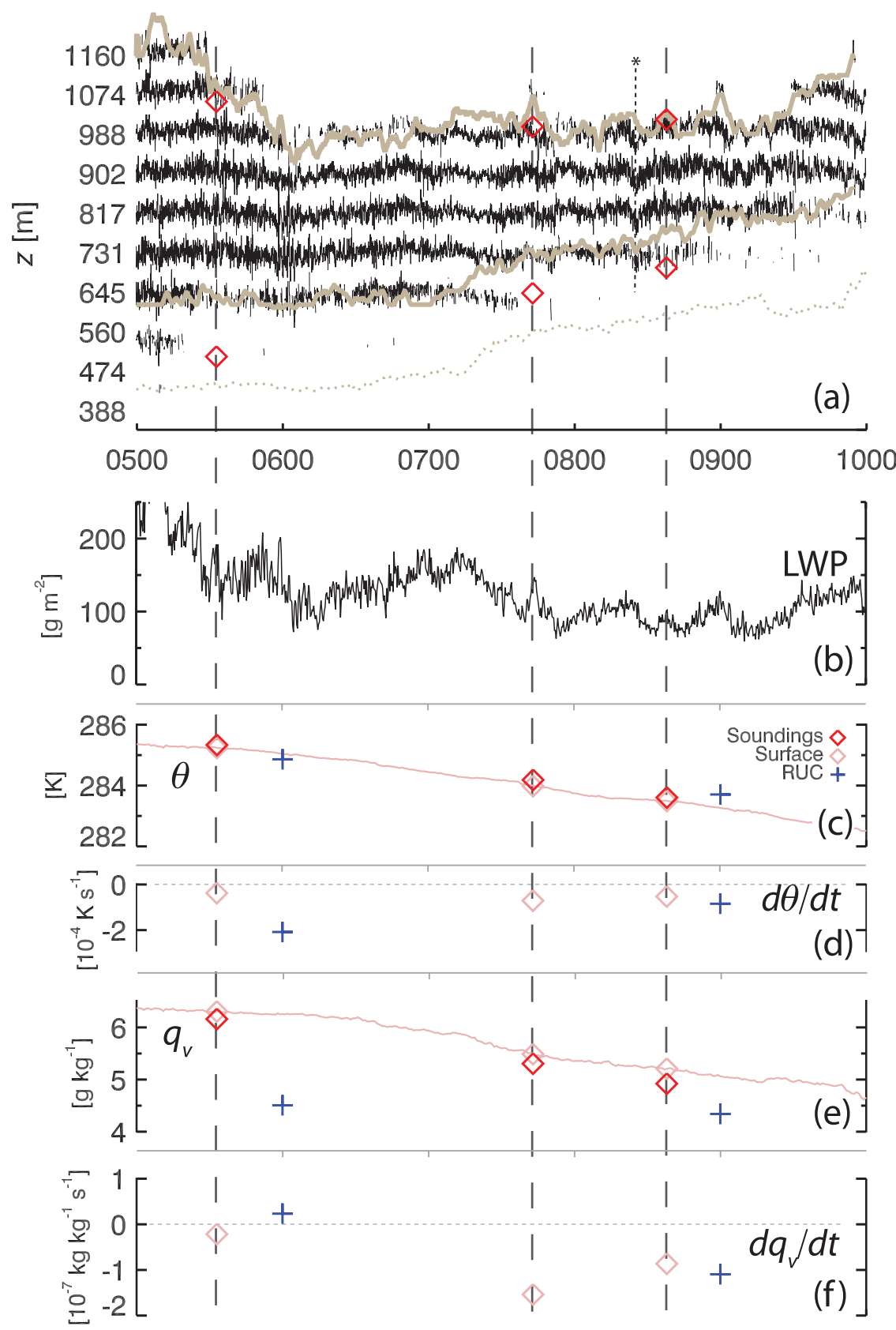

FIG. 7. Time series of cloud and boundary layer properties. (a) Doppler velocity in the cloud. For visual clarity, only every other range gate is plotted. The velocity difference between plotted gates is $2 \mathrm{~m} \mathrm{~s}^{-1}$. Solid gray lines indicate cloud base and top, as estimated by the WACR and micropulse lidar. The gray dotted line represents the LCL, calculated from surface temperature and humidity measurements. Diamonds in the velocity panel represent estimates of cloud top and cloud base obtained by radiosonde. The short-dashed line below the asterisk indicates a coherent vertical velocity structure. (b) Liquid water path retrieved from the microwave radiometer. (c) Potential temperature and (d) potential temperature advection at $500 \mathrm{~m}$ AGL obtained from soundings, surface observations, and RUC output. (e) Water vapor mixing ratio and (f) mixing ratio advection at $500 \mathrm{~m}$. The tendency panels contain $500 \mathrm{~m} \mathrm{AGL}$ horizontal advection calculated from the RUC analysis and mean surface temperature and moisture tendencies calculated over 1-h windows centered on the sounding times. 


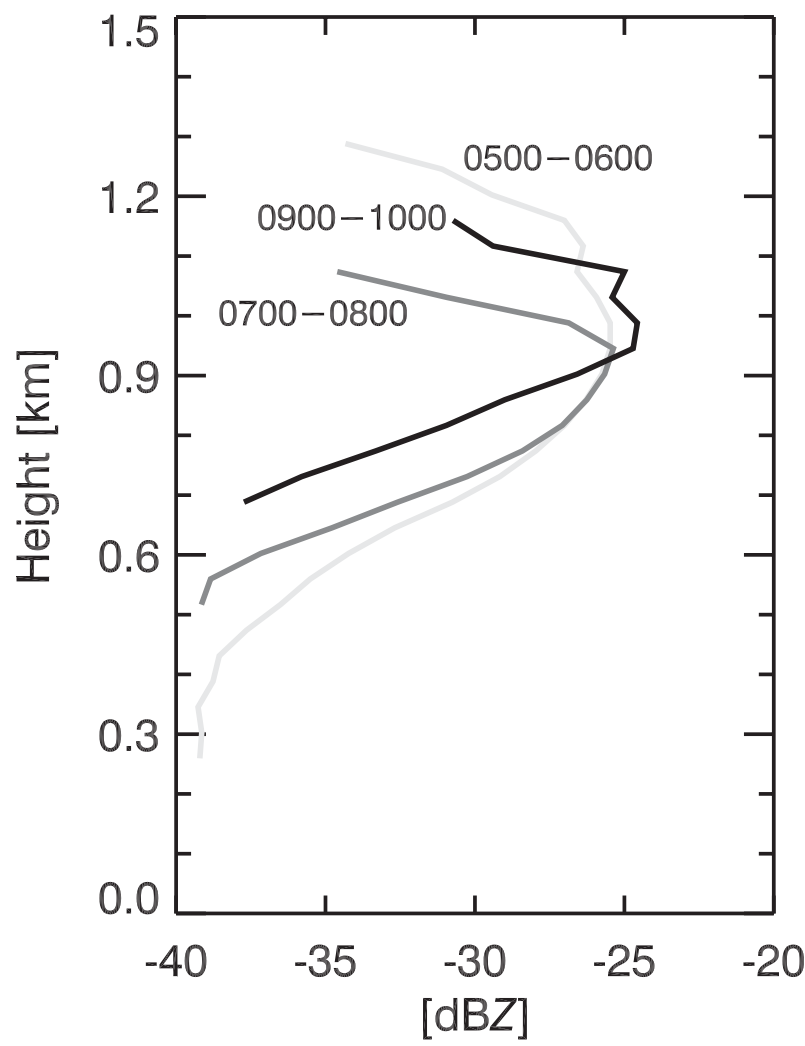

FIG. 8. Mean reflectivity profiles taken over the indicated time (UTC) intervals.

not a sharp, inversion. Because of the reduced stability in the gradual inversion, we would expect cloud to penetrate into this layer, leading to the maximum of cloud liquid water content lying lower in the cloud profile at $900 \mathrm{~m}$ (which the reflectivity profile in Fig. 8 implies). Depending on whether the gradual profile is due predominantly to cloud-top variability or internal liquid water content structure, use of a normalized vertical coordinate may result in a sharper gradient. The reflectivity profile at 0700-0800 UTC exhibits a sharp gradient similar to the thermodynamic profile at the inversion at 0743 UTC in Fig. 4a.

The minimum and maximum vertical velocities in this case were weak $\left(-2.3\right.$ and $\left.1.7 \mathrm{~m} \mathrm{~s}^{-1}\right)$, relative to the absolute minimum and maximum values of -4 and $3.5 \mathrm{~m} \mathrm{~s}^{-1}$ in Kollias and Albrecht (2000). The velocity measurements in Fig. 7 indicate highly coherent turbulent boundary layer structures, a result also seen from the vertically aligned structures in Fig. 6. For example, all radar gates at 0820 UTC (indicated by the shortdashed line below the asterisk in Fig. 7a) show a relative minimum velocity, as do those gates omitted for clarity. Evidence of mesoscale variability is evident in the lowerfrequency oscillation from 0600 to 0800 UTC.

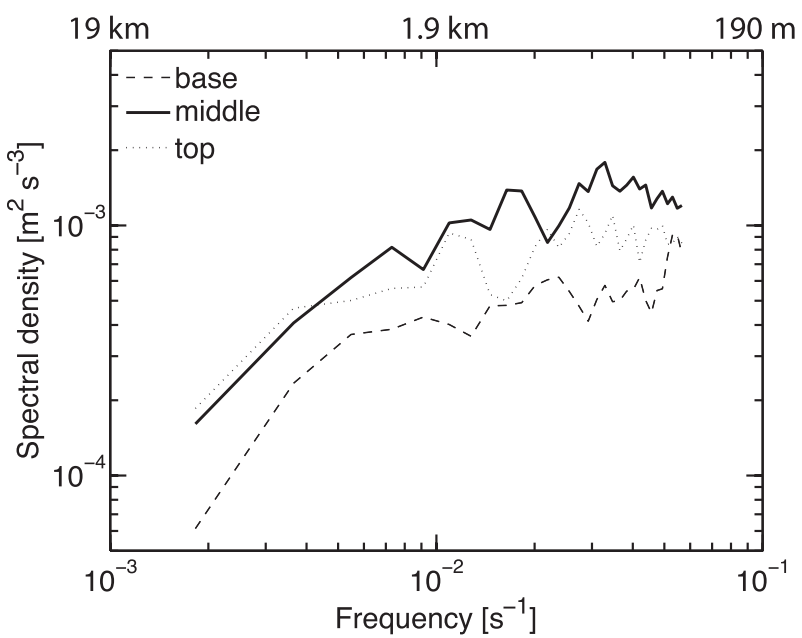

FIG. 9. Power spectra of vertical velocity at the bottom, the middle (0.5), and the top of the cloud in Fig. 7a. The spatial scale along the top axis corresponds to an advection speed of $19 \mathrm{~m} \mathrm{~s}^{-1}$. The total number of samples employed in the spectral calculations is 3364 , and the time series are composited into fifty-one 128-point FFTs, employing Hamming windows with $50 \%$ overlap.

\section{b. Power spectra}

Power spectra were generated from a 4-h period $(0500$ 0900 UTC) over three different heights from the data plotted in Fig. 7a. The heights employed in the analysis were just above cloud base, the middle of the cloud, and just inside cloud top. The data were composited into shorter segments for a smoother rendering of the spectra, as well as for a greater degree of statistical confidence (though we did not formally evaluate statistical significance). A disadvantage of this data-compositing approach is that it sets a lower bound on the frequency of about $2 \times 10^{-3} \mathrm{~s}^{-1}$, which corresponds to an upper bound on the period of just over $8 \mathrm{~min}$. Given that the mean wind speeds in the cloud layer were approximately $19 \mathrm{~m} \mathrm{~s}^{-1}$, by Taylor's approximation (frozen turbulence) this corresponds to an upper bound on the wavelength of $9.5 \mathrm{~km}$.

The sampling rate of the radar was rather coarse ( $4.3 \mathrm{~s}$, because the radar performs both a copolar and cross-polar scan), limiting the small scales that could be observed. Nevertheless, spectra taken in the middle of the cloud appear to demonstrate a peak frequency of about $0.03-0.04 \mathrm{~s}^{-1}$ (Fig. 9), which, given the mean flow of $19 \mathrm{~m} \mathrm{~s}^{-1}$, corresponds to a spatial scale between 475 and $630 \mathrm{~m}$. Whereas the characteristic eddy size typically scales with boundary layer depth (Kaimal et al. 1976), here the spatial scale was significantly smaller than the boundary layer depth $(\sim 1 \mathrm{~km})$. This result is further evidence of two distinct circulations (subcloud and cloud layer) in the boundary layer.

The spectral peaks corresponding to vertical velocity at cloud top and base were similar to that taken through 


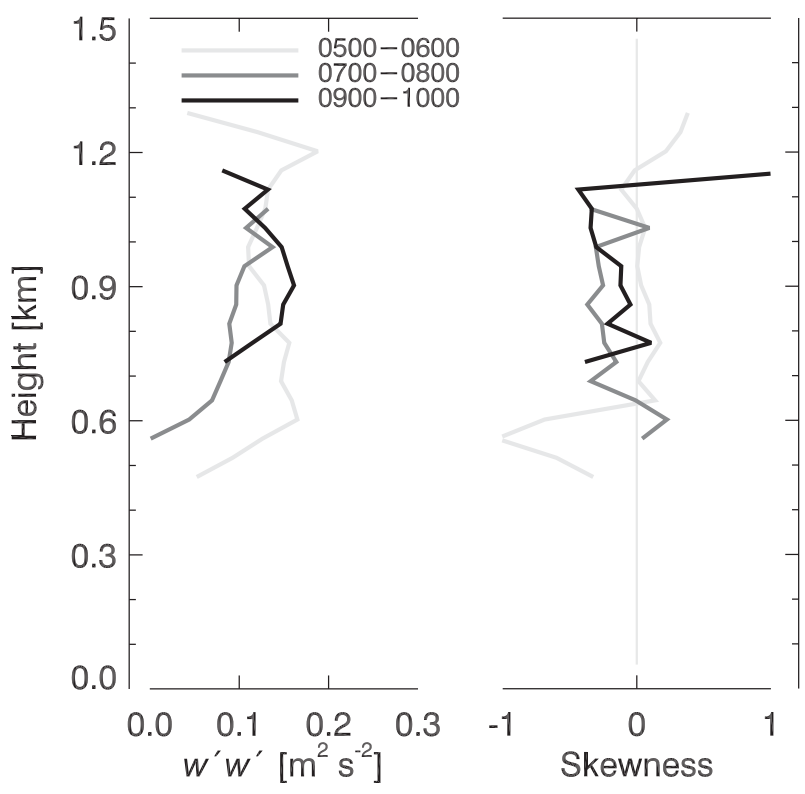

FIG. 10. Vertical profiles of variance and skewness from the WACR data for the indicated time (UTC) intervals. Each profile was calculated from 841 radar scans (samples).

the middle of the cloud (Fig. 9), which seems consistent with the degree of vertical coherence in the time series visible in Fig. 7. The energy associated with all scales was generally greatest in midcloud (Fig. 9). This result is similar to the spectra calculated in Kollias and Albrecht (2000) (their Fig. 13) and is consistent with a cloud layer driven in a top-down fashion by negative buoyancy associated with cloud-top cooling.

\section{c. Variance, skewness, and distributions of LEOs}

Profiles of vertical velocity variance in Fig. 10a for three different hourly periods seem to indicate two distinct cloud behaviors. During the first period (0500-0600 UTC) when the boundary layer was transitioning out of a thicker, precipitating cloud structure, the variance contained peaks near the top and bottom of the cloud. Over the other periods (0700-0800 and 0900-1000 UTC), conditions more typical of cloud-top boundary layers were established, and the peak vertical velocity was found in the middle or upper portion of the cloud layer.

Between 0500 and 1000 UTC, the magnitude of the vertical velocity variance, a measure of the turbulent intensity, remained roughly steady, even as the cloud thinned with time (Fig. 10a). The vertical velocity variance (maximum of $\sim 0.12-0.16 \mathrm{~m}^{2} \mathrm{~s}^{-2}$ ) was similar for the two later intervals and, despite being a nocturnal case (without the effects of solar radiation stabilizing the cloud layer), was less than in the continental stratocumulus study of Kollias and Albrecht (2000) (maximum of $\left.\sim 0.2-0.7 \mathrm{~m}^{2} \mathrm{~s}^{-2}\right)$, as well as the Atlantic marine stratocumulus case of Frisch et al. (1995b) $\left(\sim 0.18-0.23 \mathrm{~m}^{2} \mathrm{~s}^{-2}\right)$ and large-eddy simulations of marine stratocumulus (e.g., Moeng et al. 1996; Stevens et al. 2005) ( $\sim 0.3$ and $\sim 0.28 \mathrm{~m}^{2} \mathrm{~s}^{-2}$, respectively, for the ensemble mean in each series of simulations).

The reduced turbulent intensity in some cases may be attributed to the existence of multiple cloud layers. In general, multiple cloud layers decrease the net radiative flux at cloud top and thus reduce the cooling that drives boundary layer dynamics [e.g., the multilayer cloud analysis of Falk and Larson (2007)]. This particular case, however, contained only a single cloud layer, so we can remove from consideration this reason for the small magnitude of turbulence. We speculate that the reduced turbulent intensity may be attributed to the lack of evaporative enhancement accompanying entrainment (buoyancy reversal; Siems et al. 1990; Moeng 2000), given the result that mixing ratio slightly increased across the inversion (Figs. 4a,b).

Skewness exhibited a similar transition (Fig. 10b). In the earliest interval, 0500-0600 UTC, skewness was slightly positive over most of the cloud layer, a result typically associated with convection driven by surface fluxes rather than cloud-top cooling. This result was somewhat unexpected in our case, given the nocturnal setting and weak surface fluxes. The strong surface wind over this time period (a maximum of $12 \mathrm{~m} \mathrm{~s}^{-1}$ ) and shear over the boundary layer (Fig. 4c,d) suggest that shear-generation of turbulent kinetic energy might drive boundary layer eddies. This result is consistent with Zhu et al. (2001), who used mixed-layer theory to find that wind shear was important to the formation of two nocturnal boundary layer cloud systems over the ACRF.

Profiles of skewness over the later two intervals (Fig. $10 \mathrm{~b})$, however, were negative over the cloud layer, indicative of convection driven in a top-down fashion by cloud-top cooling, consistent with observations of Moyer and Young (1991). With the exception of one data point in the 0900-1000 UTC interval, the profiles do not capture the transition in skewness from negative to positive near the top of the cloud observed by Kollias and Albrecht (2000), a feature emphasized by Moeng and Rotunno (1990). We speculate that the differences in the skewness profile stem from the weaker flow (lower turbulent intensity) and the possible contribution of sheardriven eddies in addition to generation of turbulence by buoyancy.

The contoured frequency by altitude diagram (CFAD; Yuter and Houze 1995) of reflectivity in Fig. 11a, calculated from an hour of WACR data from 0700 to 0800 UTC, indicates the typical stratocumulus behavior of reflectivity (nominally, liquid water content) increasing with 


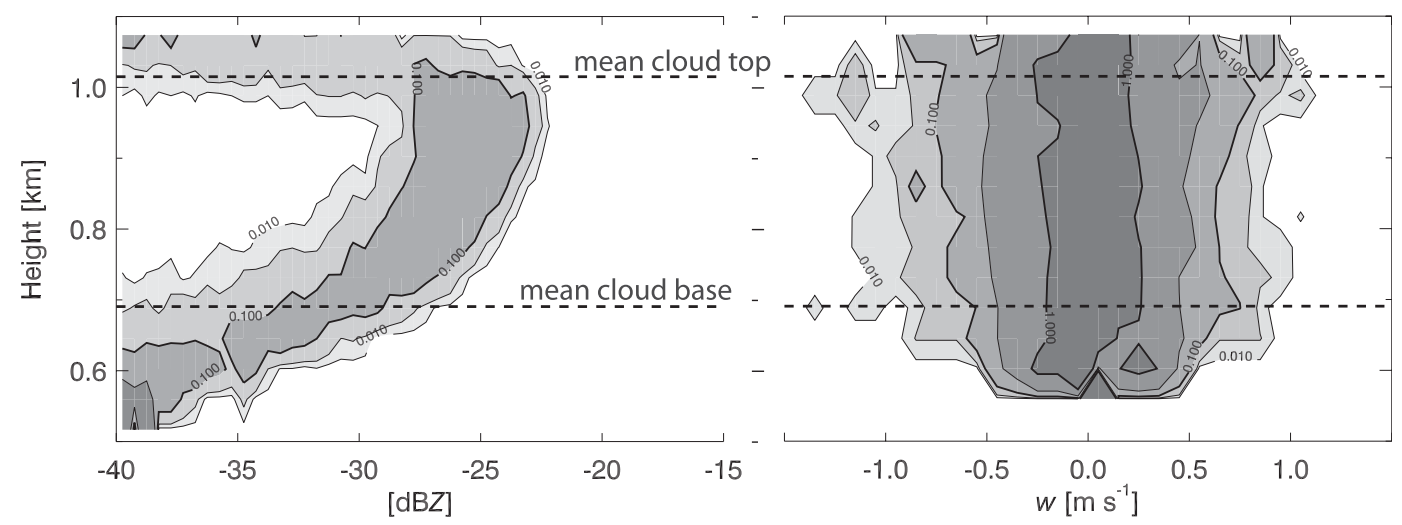

FIG. 11. CFADs of reflectivity and vertical velocity taken between 0700 and 0800 UTC. Contour values are $10^{-2}$, $10^{-1.5}, 10^{-1}, 10^{-0.5}$, and $10^{0}$, unitless because probability distribution function is the property being plotted.

height similar to that found in nonprecipitating marine stratocumulus (Frisch et al. 1995a), although we have not performed a retrieval to diagnose the degree of adiabaticity. The reflectivity above the mean cloud top indicates the vertical variability in cloud top. The instances below cloud base point toward both the variability in cloud base but also the fact that the micropulse-lidar-based estimate of cloud base was consistently higher than the radar-derived cloud base.

Visually, the distribution of vertical velocities appears nearly symmetric (Fig. 11b), but the distribution indicates a slight bias toward stronger downdrafts, as evinced by the relative positions of the 0.010 (outermost shaded) contour for positive and negative values of $w$. This slight bias is consistent with the negative skewness in Fig. 10b.

\section{d. Conditional sampling of eddy structures}

To assess the fractional area of updrafts and downdrafts, as well as their contributions to mass flux, we conditionally sampled the velocity field for different magnitudes over the 0700-0800 UTC period. Formally, this sampling is equivalent to the mass-flux partitioning procedure employed by Randall et al. (1992) and Kollias and Albrecht (2000). Unlike Kollias and Albrecht (2000), who evaluated various conditional sampling strategies involving vertical and horizontal coherence of the eddy structures, we simply conditionally sampled based on the sign of the vertical velocity, recognizing the degree of coherence (visually from Fig. 7).

The total updraft fraction was about 50\% (Fig. 12a), an unsurprising result, given that the $w$ distribution in Fig. $11 \mathrm{~b}$ is nearly symmetric. Although updrafts stronger than $0.3 \mathrm{~m} \mathrm{~s}^{-1}$ covered only about one-third of the updraft area, they were responsible for about two-thirds of the updraft mass flux (Figs. 12a,b).

The local minima in both updraft fraction and updraft mass flux at about $850 \mathrm{~m}$ are not reflected in the variance
(Fig. 10a) profile and seem to be an artifact of our hourlong calculation interval rather than a physical feature of the cloud system. Some hour-long periods contained this minimum; others do not. All the periods are otherwise consistent.

The downdraft fraction and mass flux indicate a slightly greater contribution for the stronger eddies. Downdrafts stronger than $-0.3 \mathrm{~m} \mathrm{~s}^{-1}$ again covered about one-third of the downdraft area (Fig. 12c) and were responsible for nearly two-thirds of the downdraft mass flux (Fig. 12d). The presence of a small area of strong $\left(>0.9 \mathrm{~m} \mathrm{~s}^{-1}\right.$ magnitude) downdrafts is consistent with the slight negative skewness in these clouds (Fig. 10b).

\section{Summary and discussion}

We applied a multisensor, LEO approach to the analysis of a case of continental boundary layer stratocumulus located in the post-cold-frontal region of a midlatitude synoptic cyclone. The satellite-based climatology of Field and Wood (2007) concluded that boundary layer clouds occur in midlatitude cyclones, a result consistent with our own anecdotal experience. Our goal was to explore continental stratocumulus in the context of our knowledge of marine stratocumulus cloud systems, a summary of which appears in Table 1. We intend the descriptions and statistics in the marine stratocumulus section of Table 1 to be not a comprehensive assessment of every marine stratocumulus study ever conducted but rather roughly representative of marine stratocumulus behavior. The descriptions are based on a selection of both observational and modeling studies, all listed in the Table 1 caption.

The LEO approach allows us to examine changes in cloud structure and explain them in terms of boundary layer thermodynamic evolution as captured by soundings. The post-cold-frontal region was characterized by cold-air and dry-air advection associated with the northwesterly 

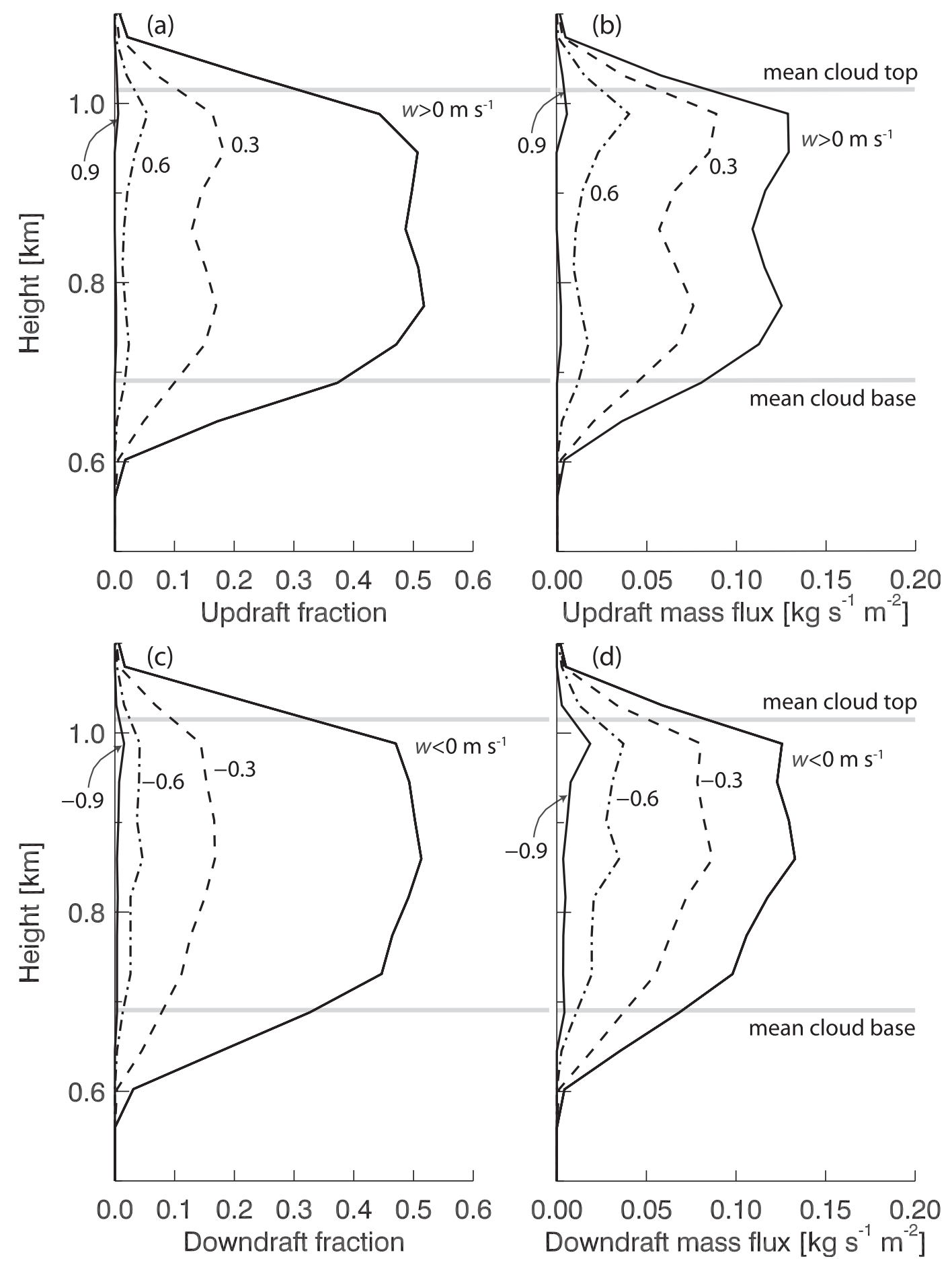

FIG. 12. Updraft and downdraft statistics, conditionally sampled by vertical velocity, calculated from the period 0700-0800 UTC. (a) Updraft fraction and (b) updraft mass flux; (c) downdraft fraction and (d) downdraft mass flux.

flow near the surface (Table 1). Vertical cross sections indicate a vertical velocity couplet over the stratocumulus that likely intensified the inversion. This vertical motion structure differs from the vertical profile of subsidence in the maritime environment. In addition, our continental case was dominated by cooling and drying in the lower troposphere in the northwesterly flow behind the cyclone, whereas advection in the marine cases is typically much 
TABLE 1. Comparison of nocturnal, nonprecipitating marine and continental stratocumulus cloud systems. Statistics for marine stratocumulus are based on observational studies of Nicholls and Leighton (1986), Bretherton et al. (1995), Frisch et al. (1995b), and Stevens et al. (2007), and on the modeling work of Deardorff (1980), Moeng et al. (1996), and Stevens et al. (2005).

\begin{tabular}{|c|c|c|}
\hline Property & Marine stratocumulus & $\begin{array}{l}\text { Continental stratocumulus } \\
\text { case of } 8 \text { Apr } 2006\end{array}$ \\
\hline Surface synoptic regime & High pressure & Low pressure \\
\hline Degree of baroclinity & Barotropic or equivalent barotropic & Baroclinic \\
\hline Temperature advection & Small & Cold-air advection \\
\hline Moisture advection & Small & Dry-air advection \\
\hline $\begin{array}{l}\text { Large-scale vertical motion field } \\
\text { at } z=1 \mathrm{~km}\end{array}$ & $\begin{array}{l}\text { Predominantly subsidence }(w \approx-1.3 \\
\left.\quad \text { to }+0.8 \mathrm{~cm} \mathrm{~s}^{-1}\right)\end{array}$ & $\begin{array}{l}\text { Weak ascent (from zero to } \\
\qquad \omega \approx-0.005 \mathrm{~Pa} \mathrm{~s}^{-1} \text { ) }\end{array}$ \\
\hline Surface moisture fluxes & $\begin{array}{l}\text { Low-level oceanic moisture source (latent } \\
\text { heat flux of } 25-150 \mathrm{~W} \mathrm{~m}^{-2} \text { ) }\end{array}$ & Small $\left(20 \mathrm{~W} \mathrm{~m}^{-2}\right)$ \\
\hline Duration of cloud system & Days to weeks & $\approx 30 \mathrm{~h}$ \\
\hline Cloud-top moisture gradient & $\begin{array}{l}\text { Large decrease }\left(2-7.5 \mathrm{~g} \mathrm{~kg}^{-1} \text { jump }\right. \\
\text { across inversion) }\end{array}$ & Negligible gradient \\
\hline $\begin{array}{l}\text { Role of cloud-top cooling in driving } \\
\text { turbulence }\end{array}$ & Important & Important \\
\hline $\begin{array}{l}\text { Relative contributions of shear and } \\
\text { buoyancy to turbulence }\end{array}$ & Buoyancy dominant & Buoyancy and shear both important \\
\hline Magnitude of in-cloud turbulence & $0.18-0.70 \mathrm{~m}^{2} \mathrm{~s}^{-2}$ & $0.12-0.16 \mathrm{~m}^{2} \mathrm{~s}^{-2}$ \\
\hline $\begin{array}{l}\text { Depth of typical boundary layer } \\
\text { eddies }\end{array}$ & $\begin{array}{l}\text { Eddies span the depth of cloud and } \\
\text { subcloud layers, or the entire } \\
\text { boundary layer }\end{array}$ & $\begin{array}{l}\text { Eddies span the depth of } \\
\text { cloud and subcloud layers }\end{array}$ \\
\hline Cloud thickness & $\begin{array}{l}\text { Highly variable from tens to hundreds } \\
\text { of meters }\end{array}$ & $250-400 \mathrm{~m}$ \\
\hline
\end{tabular}

weaker. In contrast to the marine environment, the vertical moisture gradient at cloud top was negligible in our continental case.

For clouds containing little or no precipitation, the WACR was able to sample vertically coherent boundary layer turbulence structures. CFADs of reflectivity and velocity capture a cloud layer with liquid water content increasing with height, and the slight prevalence of narrow, strong downdrafts implied in the skewness profiles. The latter is characteristic of boundary layer convection driven top-down by cloud-top longwave cooling. This perspective is confirmed by the conditional sampling of vertical velocity structures (Fig. 12), which demonstrates that stronger downdrafts predominate slightly over strong updrafts.

The magnitude of in-cloud turbulence was relatively weak compared to the continental case of Kollias and Albrecht (2000) and marine stratocumulus, both observed and simulated (see references in Table 1). Although our case is only a single cloud layer, Falk and Larson (2007) suggest that multiple cloud layers in continental systems reduce cloud-top radiative cooling and the ensuing turbulence. We speculate that the smaller values of turbulence in our case, however, may be attributed to the lack of entrainment-driven evaporative feedback (buoyancy reversal mechanism) because of the lack of a strong moisture gradient across the inversion (Figs. 4a,b).

Zhu et al. (2001) argued that shear-generation of turbulent kinetic energy can contribute significantly to boundary layer energetics in developing continental stratocumulus layers. However, the small values of incloud variance in our case imply that cloud-layer turbulence was predominantly driven by radiative cooling, with little additional contribution from shear, at least for the later period, 0700-1000 UTC, when the stratocumulus properties were most steady. The possibility nevertheless remains of shear contributing to the turbulent energetics of the subcloud layer, which the radar does not sense. The profiles of $u$ and $v$ in Figs. 4c,d, which indicate relatively weak shear in the cloud layer and strong shear below, suggests the possibility of shear generating turbulence in the subcloud layer. A turbulent kinetic energy budget would show the relative contributions to turbulence from buoyancy and shear. This analysis will be reported in a companion simulation study of cases based on this particular cloud system (Mechem et al. 2010).

How representative is this case relative to other cases? This cloud system was chosen rather anecdotally, the first author having noticed the cold-frontal passage and accompanying stratocumulus while living in Norman, Oklahoma. Comparison with other low-cloud cases (e.g., the ARM March 2000 Cloud Intensive Observation Period), however, suggests that boundary layer stratocumulus accompanying cyclones in the central Great Plains is common. An observational climatology of SGP ACRF low-cloud LEOs in their synoptic context would generalize these results. 
The current study is limited by the rather coarse sampling rate of the WACR instrument, which was an engineering trade-off to gain the advantage of polarization diversity. The WACR allowed us to observe some important features of continental boundary layer stratocumulus. We note, however, that the use of higher-resolution LEO data [similar to that employed by Kollias and Albrecht (2000), who employed a special research radar optimized for boundary layer clouds] would permit more robust estimates of stratocumulus cloud structure and more definitive analysis of its dependence on meteorological conditions.

The results of our study argue for the benefits of routine collection of large-eddy observations, along with traditional meteorological data. Perhaps the most obvious application of cloud radar LEOs like those employed in our study is to characterize the climatological behavior of the turbulent cloud dynamics, in order to supplement traditional cloud climatologies that focus on cloud structure and microphysical properties. LEOs of updraft magnitude and retrieved estimates of droplet concentration can be used to validate the assumptions behind droplet nucleation parameterizations and provide a better understanding of the aerosol-cloud interactions. Cloud parameterizations in large-scale models that rely on probability distribution functions of vertical velocity and cloud properties have generally constrained their distributions from highresolution numerical model output or educated guesses. The advent of LEOs enables systematic observations of these distributions and a resulting more accurate and complete assessment of these distributions over a broad range of conditions. Finally, though most studies simply assume the fidelity of large-eddy simulation, LEOs enable more stringent tests of LES output than previously possible, particularly when higher-order moments are compared (e.g., the comparison between LES and in situ aircraft LEOs in Guo et al. 2008).

Acknowledgments. We would like to acknowledge our fruitful conversations with Eugene Clothiaux, Pavlos Kollias, and Bruce Albrecht, who each encouraged this research. Kevin Widener and Sandra Yuter endured our questions about radar hardware and configuration. Nate Brunsell provided helpful feedback on the power spectra and boundary-layer scalings. Thanks to Kenneth Kehoe for assistance with the ARM data archive, as well as other questions related to the ARM infrastructure. Insightful and thorough input from three anonymous reviewers improved the focus of the manuscript. This investigation was supported by the University of Kansas General Research Fund allocation 230211 and New Faculty Startup funds; by the Office of Science (BER), U.S. Department of Energy, Grant DE-FG02-05ER64062, as part of the Atmospheric Radiation Measurement Program; by ONR Grants N00014-05-1-0550, N0001403-1-0304, and N00014-08-10681; and by NOAA/Office of Oceanic and Atmospheric Research under NOAAUniversity of Oklahoma Cooperative Agreement NA17RJ1227, U.S. Department of Commerce. Schultz is partially supported by Vaisala Oyj. Some of the computing for this project was performed at the OU Supercomputing Center for Education and Research (OSCER) at the University of Oklahoma.

\section{REFERENCES}

Babb, D. M., J. Verlinde, and B. A. Albrecht, 1999: Retrieval of cloud microphysical parameters from $94-\mathrm{GHz}$ radar Doppler power spectra. J. Atmos. Oceanic Technol., 16, 489-503.

Benjamin, S. G., and Coauthors, 2004a: An hourly assimilationforecast cycle: The RUC. Mon. Wea. Rev., 132, 495-518.

— , G. A. Grell, J. M. Brown, T. G. Smirnova, and R. Bleck, 2004b: Mesoscale weather prediction with the RUC hybrid isentropic-terrain-following coordinate model. Mon. Wea. Rev., 132, 473-494.

Bony, S., and J. Dufresne, 2005: Marine boundary layer clouds at the heart of tropical cloud feedback uncertainties in climate models. Geophys. Res. Lett., 32, L20806, doi:10.1029/2005GL023851.

Bretherton, C. S., P. Austin, and S. T. Siems, 1995: Cloudiness and marine boundary layer dynamics in the ASTEX Lagrangian experiments. Part II: Cloudiness, drizzle, surface fluxes, and entrainment. J. Atmos. Sci., 52, 2724-2735.

Caldwell, P., C. S. Bretherton, and R. Wood, 2005: Mixed-layer budget analysis of the diurnal cycle of entrainment in southeast Pacific stratocumulus. J. Atmos. Sci., 62, 3775-3791.

Chin, H.-N. S., D. J. Rodriguez, R. T. Cederwall, C. C. Chuang, A. S. Grossman, J. J. Yio, Q. Fu, and M. A. Miller, 2000: A microphysical retrieval scheme for continental low-level stratiform clouds: Impacts of the subadiabatic character on microphysical properties and radiation budgets. Mon. Wea. Rev., 128, 2511-2527.

Clothiaux, E. E., M. A. Miller, B. A. Albrecht, T. P. Ackerman, J. Verlinde, D. M. Babb, R. M. Peters, and W. J. Syrett, 1995: An evaluation of a $94-\mathrm{GHz}$ radar for remote sensing of cloud properties. J. Atmos. Oceanic Technol., 12, 201-229.

Deardorff, J. W., 1980: Stratocumulus-capped mixed layers derived from a three-dimensional model. Bound.-Layer Meteor., 18, $495-527$.

Del Genio, A. D., and A. B. Wolf, 2000: The temperature dependence of the liquid water path of low clouds in the southern Great Plains. J. Climate, 13, 3465-3486.

Dong, X., P. Minnis, and B. Xi, 2005: A climatology of midlatitude continental clouds from the ARM SGP Central Facility: Part I: Low-level cloud macrophysical, microphysical, and radiative properties. J. Climate, 18, 1391-1410.

Falk, M. J., and V. E. Larson, 2007: What causes partial cloudiness to form in multilayered midlevel clouds? A simulated case study. J. Geophys. Res., 112, D12206, doi:10.1029/2006JD007666.

Faloona, I., and Coauthors, 2005: Observations of entrainment in eastern Pacific marine stratocumulus using three conserved scalars. J. Atmos. Sci., 62, 3268-3285.

Field, P. R., and R. Wood, 2007: Precipitation and cloud structure in midlatitude cyclones. J. Climate, 20, 233-254; Corrigendum, 20, 5208 . 
Frisch, A. S., C. W. Fairall, and J. B. Snider, 1995a: Measurement of stratus cloud and drizzle parameters in ASTEX with a $\mathrm{K}_{\alpha^{-}}$ band Doppler radar and a microwave radiometer. J. Atmos. Sci., 52, 2788-2799.

- D. H. Lenschow, C. W. Fairall, W. H. Schubert, and J. S. Gibson, 1995b: Doppler radar measurements of turbulence in marine stratiform cloud during ASTEX. J. Atmos. Sci., 52, 2800-2808.

Guo, H., Y. Liu, P. H. Daum, G. I. Senum, and W.-K. Tao, 2008: Characteristics of vertical velocity in marine stratocumulus: Comparison of large eddy simulations with observations. Environ. Res. Lett., 3, 045020, doi:10.1088/1748-9326/3/4/045020.

Hogg, D. C., F. O. Guiraud, J. B. Snider, M. T. Decker, and E. R. Westwater, 1983: A steerable dual-channel microwave radiometer for measurement of water vapor and liquid in the troposphere. J. Climate Appl. Meteor., 22, 789-806.

Kaimal, J. C., J. C. Wyngaard, D. A. Haugen, O. R. Coté, Y. Izumi, S. J. Caughey, and C. J. Readings, 1976: Turbulence structure in the convective boundary layer. J. Atmos. Sci., 33, 2152-2168.

Kato, S., G. G. Mace, E. E. Clothiaux, J. C. Liljegren, and R. T. Austin, 2001: Doppler cloud radar derived drop size distributions in liquid water stratus clouds. J. Atmos. Sci., 58, 2895-2911.

Kim, B.-G., S. A. Klein, and J. R. Norris, 2005: Continental liquid water cloud variability and its parameterization using Atmospheric Radiation Measurement data. J. Geophys. Res., 110, D15S08, doi:10.1029/2004JD005122.

Klein, S. A., and D. L. Hartmann, 1993: The seasonal cycle of low stratiform clouds. J. Climate, 6, 1587-1606.

Kogan, Z. N., D. B. Mechem, and Y. L. Kogan, 2005: Assessment of variability in continental low stratiform clouds based on observations of radar reflectivity. J. Geophys. Res., 110, D18205, doi:10.1029/2005JD006158.

Kollias, P., and B. Albrecht, 2000: The turbulence structure in a continental stratocumulus clouds from millimeter-wavelength radar observations. J. Atmos. Sci., 57, 2417-2434.

_, E. E. Clothiaux, M. A. Miller, B. A. Albrecht, G. L. Stephens, and T. P. Ackerman, 2007a: Millimeter-wavelength radars: New frontier in atmospheric cloud and precipitation research. Bull. Amer. Meteor. Soc., 88, 1608-1624.

$\longrightarrow$, — - E. P. Luke, K. L. Johnson, K. P. Moran, K. B. Widener, and B. A. Albrecht, 2007b: The Atmospheric Measurement Program cloud profiling radars: Second-generation sampling strategies, processing, and cloud data products. J. Atmos. Oceanic Technol., 24, 1199-1214.

Liu, Y., B. Geerts, M. Miller, P. Daum, and R. McGraw, 2008: Threshold radar reflectivity for drizzling clouds. Geophys. Res. Lett., 35, L03807, doi:10.1029/2003GL031201.

Mechem, D. B., Y. L. Kogan, and D. M. Schultz, 2010: Large-eddy simulation of post-cold-frontal continental stratocumulus. $J$. Atmos. Sci., in press.

Medeiros, B., B. Stevens, I. M. Held, M. Zhao, D. L. Williamson, J. G. Olson, and C. S. Bretherton, 2008: Aquaplanets, climate sensitivity, and low clouds. J. Climate, 21, 4974-4991.

Moeng, C.-H., 2000: Entrainment rate, cloud fraction, and liquid water path of PBL stratocumulus clouds. J. Atmos. Sci., 57, 3627-3643.

—, and R. Rotunno, 1990: Vertical-velocity skewness in the buoyancy-driven boundary layer. J. Atmos. Sci., 47, 1149-1162.

— , and Coauthors, 1996: Simulation of a stratocumulus-topped planetary boundary layer: Intercomparison among different numerical codes. Bull. Amer. Meteor. Soc., 77, 261-278.
Moyer, K. A., and G. S. Young, 1991: Observations of vertical velocity skewness within the marine stratocumulus-topped boundary layer. J. Atmos. Sci., 48, 403-410.

Nicholls, S., and J. Leighton, 1986: An observational study of the structure of stratiform cloud sheets: Part I. Structure. Quart. J. Roy. Meteor. Soc., 112, 431-460.

Ramanathan, V., R. D. Cess, E. F. Harrison, P. Minnis, B. R. Barkstrom, E. Ahmad, and D. Hartmann, 1989: Cloud-radiative forcing and climate: Results from the Earth Radiation Budget Experiment. Science, 243, 57-63.

Randall, D. A., Q. Shao, and C.-H. Moeng, 1992: A second-order bulk boundary layer model. J. Atmos. Sci., 49, 1903-1923.

Sassen, K., G. G. Mace, Z. Wang, M. R. Poellot, S. M. Sekelsky, and R. E. McIntosh, 1999: Continental stratus clouds: A case study using coordinated remote sensing and aircraft measurements. J. Atmos. Sci., 56, 2345-2358.

Schultz, D. M., 2008: Perspectives of Fred Sanders' research on cold fronts. Synoptic-Dynamic Meteorology and Weather Analysis and Forecasting: A Tribute to Fred Sanders, Meteor. Monogr., No. 55, Amer. Meteor. Soc., 109-126.

, and P. J. Roebber, 2008: The fiftieth anniversary of Sanders (1955): A mesoscale-model simulation of the cold front of 17-18 April 1953. Synoptic-Dynamic Meteorology and Weather Analysis and Forecasting: A Tribute to Fred Sanders, Meteor. Monogr., No. 55, Amer. Meteor. Soc., 127-143.

Siems, S. T., C. S. Bretherton, M. B. Baker, S. S. Shy, and R. E. Breidenthal, 1990: Buoyancy reversal and cloud-top entrainment instability. Quart. J. Roy. Meteor. Soc., 116, 705-739.

Stevens, B., and Coauthors, 2003: Dynamics and chemistry of marine stratocumulus-DYCOMS-II. Bull. Amer. Meteor. Soc., 84, 579-593.

- and Coauthors, 2005: Evaluation of large-eddy simulations via observations of nocturnal marine stratocumulus. Mon. Wea. Rev., 133, 1443-1462.

, A. Beljaars, S. Bordoni, C. Holloway, M. Köhler, S. Krueger, V. Savic-Jovcic, and Y. Zhang, 2007: On the structure of the lower troposphere in the summertime stratocumulus regime of the northeast Pacific. Mon. Wea. Rev., 135, 985-1005.

Vali, G., R. D. Kelly, J. French, S. Haimov, D. Leon, R. E. McIntosh, and A. Pazmany, 1998: Finescale structure and microphysics of coastal stratus. J. Atmos. Sci., 55, 3540-3564.

van Zanten, M. C., B. Stevens, G. Vali, and D. H. Lenschow, 2005: Observations of drizzle in nocturnal marine stratocumulus. J. Atmos. Sci., 62, 88-106.

Widener, K. B., and K. Johnson, 2006: W-band ARM Cloud Radar (WACR) Handbook. ARM Tech. Rep. ARM TR-073, Office of Science, Office of Biological and Environmental Research, U.S. Department of Energy, 14 pp.

Williams, K. D., and M. J. Webb, 2009: A quantitative performance assessment of cloud regimes in climate models. Climate Dyn., 33, 141-157.

Wood, R., and C. S. Bretherton, 2004: Boundary layer depth, entrainment, and decoupling in the cloud-capped subtropical and tropical marine boundary layer. J. Climate, 17, 35763588.

Yuter, S. E., and R. A. Houze Jr., 1995: Three-dimensional kinematic and microphysical evolution of Florida cumulonimbus. Part II: Frequency distribution of vertical velocity, reflectivity, and differential reflectivity. Mon. Wea. Rev., 123, 1941-1963.

Zhu, P., B. Albrecht, and J. Gottschalck, 2001: Development of nocturnal boundary layer clouds over the southern Great Plains. J. Atmos. Sci., 58, 1409-1426. 